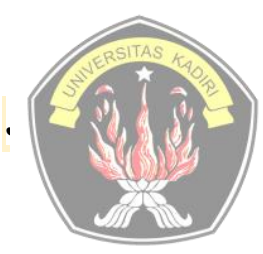

Tersedia online di

\title{
Analisis Harga, Inovasi Produk, Promosi dan Proses Bisnis Terhadap Kepuasan Konsumen Bakso Aci Tata Snack
}

\author{
Marwita Andarini ${ }^{1}$, Nur Laely ${ }^{2}$, Wigati $^{3}$, Nurul Laily ${ }^{4}$ \\ ${ }^{1,2}$ Fakultas Ekonomi, Universitas Kadiri \\ 3,4 Mahasiswa Magister Manajemen Universitas Kadiri \\ email: marwita_andarini@unik-kediri.ac.id; nurlaely@unik-kediri.ac.id; \\ wigati201@gmail.com; nurullaily@unik-kediri.ac.id
}

\section{Artikel History:}

Artikel masuk : 20-08-2019

Artikel revisi : 26-09-2019

Artikel diterima : 29-09-2020

\section{Keywords:}

Price;

Product Innovation;

Promotion;

Business Process;

Customer Satisfaction

\begin{abstract}
ABSTRAK
Perkembangan produk makanan khususnya produk camilan yang memiliki daya tarik untuk dicoba dan dilakukan penelitian ini, adalah produk bakso aci yang diproduksi oleh Tata Snack, yang berlokasi di Ngadiluwih, Kediri. Penelitian ini bertujuan untuk mengetahui pengaruh harga, inovasi produk, promosi dan proses bisnis terhadap kepuasan konsumen secara parsial dan simultan. Populasi yang digunakan sebesar 163 konsumen yang didapat dari data pembelian sejak 1 Desember 2019 sampai dengan 30 Januari 2020. Besarnya sampel pada penelitian ini menggunakan rumus Slovin, dengan sampel responden sejumlah 116 orang. Responden tersebut dihubungi untuk mengisi kuisioner secara online sebanyak 116 responden, kemudian dilakukan rekapitulasi data dengan jumlah 116 responden. Dilanjutkan uji regresi linier berganda dengan hasil jika kepuasan konsumen bekerja 1 satuan terhadap harga meningkat sebesar 0,05 , inovasi meningkat sebesar 0,146 , promosi meningkat sebesar 0,058 dan proses bisnis meningkat sebesar 0,402. Secara parsial variabel tersebut tidak berpengaruh signifikan terhadap kepuasan konsumen, sedangkan secara simultan variabel bebas mampu bekerja bersama - sama dan variabel yang paling berpengaruh adalah inovasi produk. Penelitian ini memiliki prosentase sebesar $73,4 \%$ yang dapat dijelaskan, sedangkan sisanya sebesar 0,266 tidak dijelaskan pada penelitian ini.
\end{abstract}

\section{ABSTRACT}

The development of food products, especially snack products, which has an attraction to try and carry out this research, is the aci meatball product produced by Tata Snack, which is located in Ngadiluwih, Kediri. This study aims to determine the effect of price, product innovation, promotion and business processes on customer satisfaction partially and simultaneously. The population used was 163 consumers obtained from purchase data from December 1, 2019 to January 30, 2020. The sample size in this study used the Slovin formula, with a sample of 116 respondents. The 116 respondents contacted to fill out an online questionnaire, then recapitulated the data with a total of 116 respondents. 
Followed by multiple linear regression test with the results if the customer satisfaction with one unit of work increased by 0.05 , innovation increased by 0.146 , promotion increased by 0.058 and business processes increased by 0.402. Partially these variables do not have a significant effect on customer satisfaction, while simultaneously the independent variables are able to work together and the most influential variable is product innovation. This study has a percentage of $73.4 \%$ which can be explained, while the remaining 0.266 is not explained in this study

\section{PENDAHULUAN}

Perkembangan inovasi berubah semakin cepat yang dapat memberikan pengaruh pada perkembangan produk kuliner khususnya makanan. Pengembangan produk dari makanan agar memiliki tingkat pembelian yang tinggi diperlukan faktor - faktor yang berkaitan dengan pemasaran. Dalam hal ini suatu produk makanan memiliki strategi - strategi yang digunakan untuk meningkatkan keputusan pembelian. Menurut (Komari, 2016) strategi adalah aktivitas yang bertujuan untuk melakukan implementasi misi - misi dengan kunci keberhasilan dalam menghadapi persoalan ada lingkungan bisnis yang dijalankan dengan fungsi memberikan arah yang positif sesuai harapan organisasinya. Didalam strategi yang dijalankan memiliki aspek pemasaran yaitu : produk, harga, promosi dan tempat. Product (produk) menurut (Stanton, 1993), kumpulan dari atribut yang nyata dan tidak nyata dengan cangkupan yang mampu diterima oleh pembeli sebagai pemuas konsumsi dalam bentuk jasa atau barang. Menurut (Tjiptono \& Chandra, 2017), Price (Harga)adalah nilai yang relatif sebagai cara yang digunakan untuk menghasilkan produk. Menurut (Tjiptono, 2015), Promotion (Promosi) adalah suatu faktor untuk menentukan keberhasilan dari aktivitas pemasaran yang dilakukan oleh organisasi. Menurut (Ghazzan, 2012), Place (tempat) adalah tempat yang digunakan untuk menjalankan bisnis dengan meninjau lokasi yang strategis, akses yang mudah dan konsumen yang datang kelokasi dapat dengan mudah menemukan. Dalam empat aspek tersebut dinamakan bauran pemasaran, bahwa didalam penelitian (Komari, Sularso, \& Sumiati, 2019), harga, produk, distribusi (bauran pemasaran) dan orientasi pasar memiliki pengaruh secara signifikan terhadap starategi didalam bisnis. Oleh sebab itu, bauran pemasaran selalu digunakan untuk melakukan evaluasi pada usaha - usaha bisnis. Didalam bauran pemasaran (4P) menurut (Kotler, Kartajaya, \& Setiawan, 2017), menegaskan bahwa tidak hanya empat aspek, melainkan ada tujuan aspek (7P) dengan ditambahkan aspek : people (orang), physical evidence (bukti fisik), dan process (proses). Didalam pengertian people (orang), sebagai sumber daya manusia yang digunakan untuk melakukan kegiatan pemenuhan kebutuhan konsumen untuk memberikan kepuasan dan loyalitas (Saidani \& R Sudiarditha, 2019). Sedangkan physical evidence (bukti 
fisik) adalah syarat yang digunakan sebagai nilai tambah dari adanya perusahaan. Dalam hal ini perhatian utaman berada pada kondisi ruangan, perlengkapan bangunan dan tata ruang untuk meningkatkan daya tarik konsumen ketika melakukan pemesanan produk di lokasi (Widyatama, 2016), dan process (proses) adalah sebagai alat yang menjamin penyampaian produk kepada konsumen, yang berkaitan dengan mutu pelayanan, aktivitas operasional, komitmen yang sudah dibangun dan keloyalan tenaga kerja terhadap perusahaan (Kushwaha \& Agrawal, 2015).

Didalam berlangsungnya kegiatan pembelian suatu produk, konsumen akan memiliki rasa yang akan diungkapkan terhada produk tersebut. Salah satu rasa ungkapan adalah kepuasan pembelian. Didalam kepuasan pembelian diartikan sebagai dampak berupa perasaan senang atau kecewa yang muncul dari konsumen setelah melakukan perbandingan dari persepsi dengan hasil dari produk dan harapan yang didapat, apakah sesuai atau tidak. Dalam hal ini, persepsi dan harapan mampu memberikan kepuasan atau ketidakpuasan pada konsumen. Jika konsumen puas, maka mampu memenuhi harapan pelanggan, sedangkan jika melebihi harapan dianggap sangat puas dan sebaliknya jika persepsi dan harapan tidak didapatkan oleh konsumen, dianggap kepuasan tidak tercapai (Farida, Tarmizi, \& November, 2016). Didalam penelitian (Daragahi, 2017), bahwa didalam kepuasan pelanggan mampu memberikan elemen unci sebagai cara meningkatkan persaingan dan sebuah kepuasan akan didasari pada inovasi produk, tawar menawar harga, proses produksi dan cara pemasaran produk. Oleh karena itu, dari inovasi produk, pemasaran, harga sangat memiliki kaitan. Kepuasan pembelian suatu produk juga didukung adanya loyalitas yang diperkuat penelitian yang dilakukan oleh (Rasmansyah, 2017), yaitu kepuasan konsumen akan memiliki pengaruh terhadap kualitas pelayanan yang diberikan kemudian adanya promosi yang saling bekerja untuk menghasilkan nilai kepuasam yang mendekati loyalitas. Setelah terjadi kepuasan yang amat puas dari persepsi dan harapan konsumen, puncaknya akan berada pada loyalitas, bahwa setiap produk yang dipasarkan dipastikan konsumen akan melakukan pembelian. Terkait dengan kepuasan konsumen, didalam penelitian (Subaebasni et al., 2019), bahwa citra merk, kualitas produk dan harga mampu memberikan pengaruh terhadap kepuasan pelanggan, kemudian digunakan implikasi sebagai jika terjadi kepuasan pelanggan secara konsisten akan berujung menjadi loyalitas pelanggan yaitu melakukan konsumsi sebuah produk karena pelanggan sudah setiap terhadap produk yang dikonsumsinya atau digunakan untuk kebutuhannya.

Salah satu produk camilan yang memiliki daya tarik untuk dicoba dan dilakukan penelitian ini, adalah produk bakso aci yang diproduksi oleh Tata Snack, yang berlokasi di Ngadiluwih, Kediri. Dalam usaha tersebut, ada inovasi produk yang diberikan salah satunya adalah produk 
memiliki masa kadaluarsa dan dapat dikonsumsi tidak saat langsung dibeli. Kemudian dari segi harga berbanding lurus dengan kualitas rasa. Promosi yang dilakukan menggunakan media online dan offline, kemudian dari proses bisnis yang dilakukan pengiriman sesuai jadwal harapan konsumen. Dari uraian latar belakang, diperlukan pengetahuan tentang apakah kepuasan yang didapat konsumen sesuai dengan ekspetasi dan harapannya. Penelitian ini memiliki rumusan masalah dan bertujuan untuk mengetahui pengaruh inovasi produk, harga, promosi, aktivitas bisnis terhadap kepuasan pembelian secara parsial, kemudian untuk mengetahui pengaruh inovasi produk, harga, promosi, proses bisnis terhadap kepuasan pembelian secara simultan dan dari variabel bebas tersebut perlu diketahui manakah yang paling berpengaruh. Penelitian memiliki memiliki dugaan penelitiaa yaitu :

Secara parsial :

1. $\mathrm{H}_{0}=$ Adanya pengaruh harga, inovasi produk, promosi, aktivitas bisnis terhadap kepuasan pembelian secara parsial

2. $\mathrm{H}_{\mathrm{a}}=$ Tidak adanya pengaruh harga, inovasi produk, promosi, aktivitas bisnis terhadap kepuasan pembelian secara parsial

Secara simultan :

1. $\mathrm{H}_{0}=$ Adanya pengaruh harga, inovasi produk, promosi, aktivitas bisnis terhadap kepuasan pembelian secara simultan

2. $\mathrm{H}_{\mathrm{a}}=$ Tidak adanya pengaruh harga, inovasi produk, promosi, aktivitas bisnis terhadap kepuasan pembelian secara simultan

Kerangka berpikir sebagai berikut :

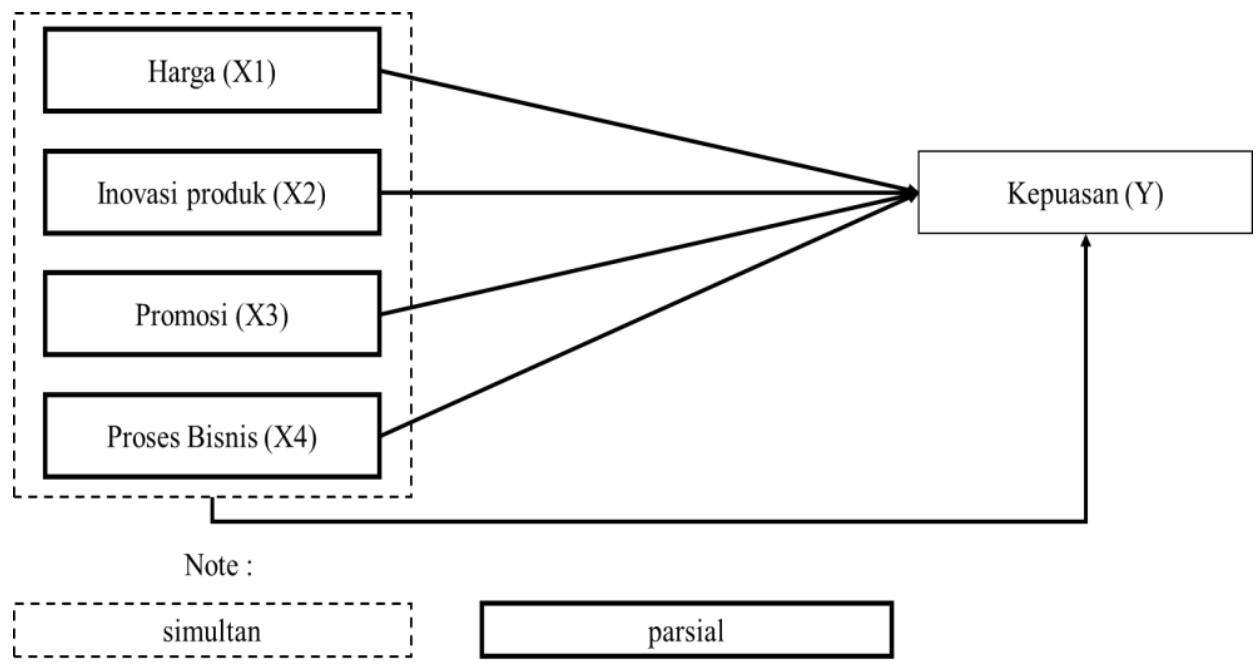

Gambar 1 Kerangka berpikir

Batasan pada penelitian ini, yaitu melakukan penelitian terkait variabel harga, inovasi produk, promosi, proses bisnis terhadap kepuasan. Sedangkan pada asumis yang digunakan 
adalah pengambilan data responden berasal dari riwayat pembelian dalam kurun waktu 1 Desember 2019 sampai dengan 30 Januari 2020 tanpa ada perubahan data, kemudian menghubungi responden sesuai sampel yang digunakan dan menyebarkan kuisioner melalui media WhatsApps.

\section{TINJAUAN PUSTAKA}

\section{METODE PENELITIAN}

\section{Tempat dan Waktu Penelitian}

Penelitian dilakukan pada Tata Snack yaitu bisnis rumahan yang menjual bakso aci, yang dilakukan penelitian sejak 15 Januari 2020 sampai dengan 25 Januari 2020.

\section{Populasi dan Sampel}

Pada penelitian ini populasi adalah konsumen yang berasal dari Kota Kediri dengan jumlah 163 konsumen pada riwayat pembelian bakso aci berdasarkan data dari Tata Snack sejak 1 Desember 2019 sampai dengan 30 Januari 2020. Sedangkan sampel penelitian dilakukan margin of error sebesar 5\%, menggunakan rumus Slovin sebagai berikut :

$$
n=\frac{N}{1+N e^{2}}
$$

Keterangan :

$\mathrm{N}=$ jumlah populasi

$\mathrm{e}=$ margin of error $(5 \%)$

Maka, besar sampel yang digunakan untuk melakukan penelitian ini adalah sebagai berikut :

$$
n=\frac{163}{1+\left(163 \times\left(0,05^{2}\right)\right.}=115,8 \text { dibulatkan } 116 \text { reponden }
$$

\section{Subjek dan Objek Penelitian}

Subjek penelitian ini adalah bisnis bakso aci Tata Snack dimana tempat tersebut digunakan untuk penelitian mencari informasi tentang tentang data yang mendukung topik penelitian. Sedangkan obyek penelitian adalah terkait pemasaran dengan topik Analisis Harga, Inovasi Produk, Promosi dan Aktivitas Bisnis Terhadap Kepuasan Pembelian Bakso Aci Tata Snack.

\section{Variabel Operasional}


Tabel 1 Variabel Operasional

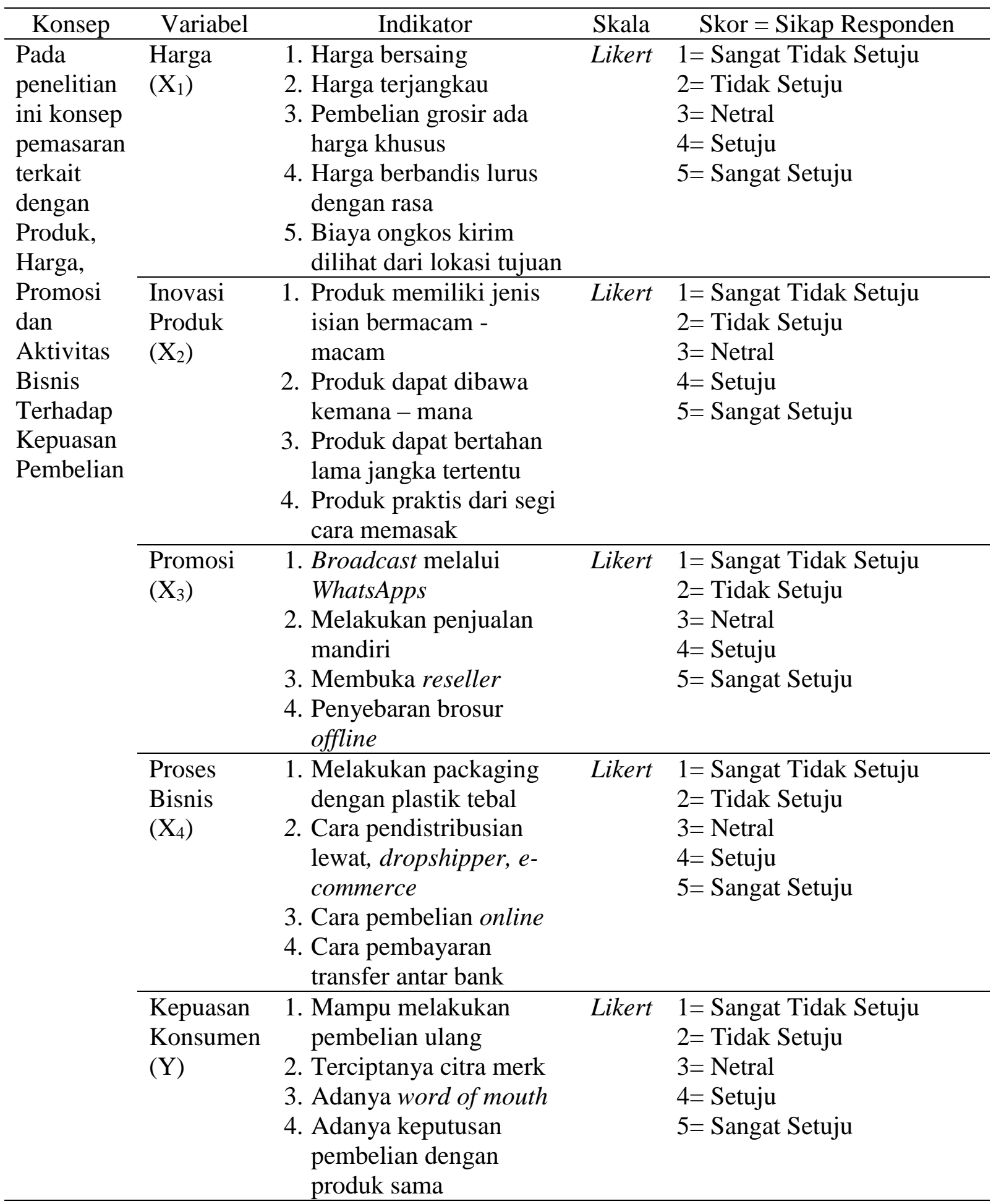

\section{Jenis dan Sumber Data}

Jenis data sebagai berikut :

1. Data kualitatif adalah data yang disajikan secara verbal bukan bentuk angka (Semiawan, 2010). 
2. Data kuantitatif adalah data yang dapat diukur secara langsung, atau penjelasan yang berbentuk angka sesuai dengan topik penelitian” (Dr. Whidmurni, 2017).

Sumber data sebagai berikut :

1. Data primer adalah data yang dikumpulkan secara langsung dari sumber penelitian (Ali Maksum, 2012).

2. Data sekunder adalah data yang dikumpulkan sebaga langkah untuk memperkuat data primer (Ali Maksum, 2012).

Tabel 2 Jenis dan Sumber Data

\begin{tabular}{|c|c|c|c|c|}
\hline No. & Nama data & Jenis data & $\begin{array}{c}\text { Sumber } \\
\text { data }\end{array}$ & Tempat \\
\hline 1 & Data konsumen & Kuantitatif & Primer & Tata Snack \\
\hline 2 & $\begin{array}{ll}\text { Data } & \text { pengisian } \\
\text { kuisioner } & \end{array}$ & Kuantitatif & Primer & Konsumen \\
\hline 3 & Profil Bisnis & Kualitatif & Primer & Tata Snack \\
\hline 4 & Studi Pustaka & $\begin{array}{l}\text { Kualitatif } \\
\text { kuantitatif }\end{array}$ & Sekunder & $\begin{array}{l}\text { Jurnal, Internet, } e \text { - } \\
\text { book }\end{array}$ \\
\hline
\end{tabular}

\section{Teknik Pengumpulan Data}

Pada teknik pengumpulan data sebagai berikut :

a. Observasi

Didalam kegiatan observasi pada penelitian ini dilakukan pengamatan langsung, meninjau dan mencatat segala sesuatu yang terkait dengan produk, harga, promosi dan aktivitas bisnis terhadap keputusan pembelian (Hasanah, 2017).

b. Wawancara

Fungsi dari wawancara sebagai pengumpulan data tentang bisnis bakso aci Tata Snack sebagai pendukung data yang didapat pada observasi (Ali Maksum, 2012).

c. Studi pustaka

Menurut (Agusta, 2014) data - data terkait studi pustaka bisa diperoleh melalui media internet dengan kata kunci terkait topik penelitian, kemudian dapat mengacu pada jurnal jurnal penelitian yang memiliki reputasi, baik jurnal berbahasa Indonesia maupun berbahasa Inggris.

\section{Teknik Analisis Data}

Teknik analisis data yang digunakan sebagai berikut :

1. Uji Validitas 
Uji validitas digunakan untuk mengetahui apakah data yang didapat dari pengisian kuisioner memiliki tingkat kevalidan yang dapat digunakan untuk uji selanjutnya. Cara melakukan uji validitas dapat menggunakan korelasi bivariate pearson dan correlated item - total correlation yang didapatkan analyze menggunakan software SPSS IBM Version 23.0.

2. Uji Reliabilitas

Menurut (Yusup, 2018) untuk mengetahui kereliabelan dari sebuah data - data yang diuji, dilihat pada hasil perhitungan nilai cronbach's alpha $(\alpha)>0,60$ maka variabel dinyatakan reliabel.

3. Uji Regresi Linier Berganda

Model persamaan regresi pada penelitian ini, yaitu (I Made Yuliara (Universitas Udayana), 2016):

$$
Y=a+b_{1} X_{1}+b_{2} X_{2}+b_{3} X_{3}+b_{4} X_{4} \ldots+b_{k} X_{k}
$$

Keterangan :

$\mathrm{Y}$ : nilai prediksi dari $\mathrm{Y}$

$\alpha \quad$ : nilai konstan

$b_{k} \quad$ : variabel bebas

$\mathrm{X}_{\mathrm{k}}$ : variabel independen

4. Uji T (Parsial)

Kriteria dan aturan pengujian

$\mathrm{H}_{\mathrm{o}}$ diterima apabila : $\mathrm{T}_{\text {tabel }} \geq \mathrm{T}_{\text {hitung }} ; a / 2 ; \mathrm{n}-1-\mathrm{k}$

$\mathrm{H}_{\mathrm{a}}$ ditolak apabila $: \mathrm{T}_{\text {tabel }} \leq \mathrm{T}_{\text {hitung }} ; a / 2 ; \mathrm{n}-1-\mathrm{k}$

5. Uji F (Simultan)

Kriteria dan aturan pengujian

$\mathrm{H}_{\mathrm{o}}$ diterima apabila $\mathrm{F}_{\text {hitung }} \leq \mathrm{F} 0,05 ; \mathrm{k}$; n-1-k

$\mathrm{H}_{\mathrm{a}}$ ditolak apabila $\mathrm{F}_{\text {hitung }} \geq \mathrm{F} 0,05 ; \mathrm{k} ; \mathrm{n}-1-\mathrm{k}$

Uji Koefisien Determinasi $\left(\mathrm{R}^{2}\right)$

\section{HASIL \& PEMBAHASAN}

\section{a. Uji Validitas}

Tabel 3 Uji Validitas

\begin{tabular}{ccccc}
\hline Variabel & Indikator & $\mathrm{R}_{\text {tabel }}(\mathrm{n}-2)$ & $\mathrm{R}_{\text {hitung }}$ & Keterangan \\
\hline \multirow{2}{*}{$\mathrm{X} 1$} & $\mathrm{X} 11$ & 0,1824 & 0,575 & Valid \\
\cline { 2 - 5 } & $\mathrm{X} 12$ & 0,1824 & 0,815 & Valid \\
\cline { 2 - 5 } & $\mathrm{X} 13$ & 0,1824 & 0,866 & Valid \\
\hline
\end{tabular}




\begin{tabular}{|c|c|c|c|c|}
\hline & X14 & 0,1824 & 0,505 & Valid \\
\hline \multirow[t]{4}{*}{$\mathrm{X} 2$} & $\mathrm{X} 21$ & 0,1824 & 0,577 & Valid \\
\hline & $\mathrm{X} 22$ & 0,1824 & 0,788 & Valid \\
\hline & $\mathrm{X} 23$ & 0,1824 & 0,841 & Valid \\
\hline & X24 & 0,1824 & 0,461 & Valid \\
\hline \multirow[t]{4}{*}{$\mathrm{X} 3$} & X31 & 0,1824 & 0,637 & Valid \\
\hline & X32 & 0,1824 & 0,799 & Valid \\
\hline & X33 & 0,1824 & 0,860 & Valid \\
\hline & X34 & 0,1824 & 0,503 & Valid \\
\hline \multirow[t]{4}{*}{$\mathrm{X} 4$} & $\mathrm{X} 41$ & 0,1824 & 0,576 & Valid \\
\hline & $\mathrm{X} 42$ & 0,1824 & 0,805 & Valid \\
\hline & X43 & 0,1824 & 0,857 & Valid \\
\hline & $\mathrm{X} 44$ & 0,1824 & 0,465 & Valid \\
\hline \multirow[t]{4}{*}{$\mathrm{Y}$} & Y1 & 0,1824 & 0,601 & Valid \\
\hline & Y2 & 0,1824 & 0,809 & Valid \\
\hline & Y3 & 0,1824 & 0,866 & Valid \\
\hline & Y4 & 0,1824 & 0,506 & Valid \\
\hline
\end{tabular}

Pada hasil uji validitas variabel bebas Harga (X1), Inovasi produk (X2), Promosi (X3) dan Proses bisnis (X4) dan variabel terikat kepuasan konsumen (Y) memiliki nilai $\mathrm{T}_{\text {hitung }}>$ $\mathrm{T}_{\text {tabel. }}$ Maka, dinyatakan variabel bebas dan variabel terikat dinyatakan valid.

\section{b. Uji Reliabilitas}

Tabel 4 Uji Reliabilitas

\begin{tabular}{cccc}
\hline Variabel & $\begin{array}{c}\text { Cronbach Alpha } \\
\text { Minimal }\end{array}$ & Cronbach Alpha Hitung & Keterangan \\
\hline X1 & 0,6 & 0,778 & Reliabel \\
\hline X2 & 0,6 & 0,766 & Reliabel \\
\hline X3 & 0,6 & 0,781 & Reliabel \\
\hline X4 & 0,6 & 0,771 & Reliabel \\
\hline Y & 0,6 & 0,780 & Reliabel \\
\hline
\end{tabular}

Pada hasil uji reliabilitas variabel bebas Harga (X1), Inovasi produk (X2), Promosi (X3) dan Proses bisnis (X4) dan variabel terikat kepuasan konsumen (Y) memiliki nilai

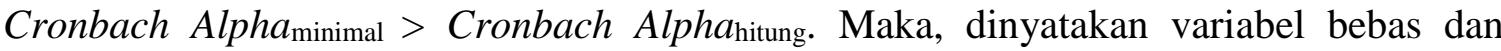
variabel terikat memiliki nilai reliabel.

\section{c. Uji Regresi Linier Berganda}

Tabel 5 Uji Regresi Linier Berganda

\begin{tabular}{cc}
\hline Model & $B$ \\
\hline$($ Constant $)$ & 1,073 \\
\hline $\mathrm{X} 1$ & 0,05 \\
\hline
\end{tabular}




\begin{tabular}{cc}
\hline $\mathrm{X} 2$ & 0,416 \\
\hline $\mathrm{X} 3$ & 0,058 \\
\hline $\mathrm{X} 4$ & 0,402 \\
\hline
\end{tabular}

Dari uji regresi linier berganda, yang dilakukan pada variabel bebas dan variabel terikat dengan model sebagai berikut :

$$
Y=1,073+0,05 X_{1}+0,416 X_{2}+0,058 X_{3}+0,402 X_{4}
$$

Dari model tersebut dijelaskan bahwa, nilai konstanta sebesar 1,073 satuan artinya variabel harga (X1), inovasi produk (X2), promosi (X3) dan proses bisnis (X4) jika tidak melakukan aktivitas untuk mencapai kepuasan konsumen (Y), maka bernilai 1,073 atau 107,3 satuan. Jika variabel bebas lainnya bernilai tetap, sedangkan variabel harga (X1) mengalami kenaikan 1 satuan maka variabel kepuasan konsumen (Y) mengalami peningkatan sebesar 0,05 atau $5 \%$. Jika variabel bebas lainnya bernilai tetap, sedangkan variabel inovasi produk (X2) mengalami kenaikan 1 satuan maka variabel kepuasan konsumen (Y) mengalami peningkatan sebesar 0,416 atau 41,6\%. Sedangkan variabel bebas lainnya bernilai tetap, kemudian variabel promosi (X3) mengalami kenaikan 1 satuan maka variabel kepuasan konsumen (Y) mengalami peningkatan sebesar 0,058. Dan pada variabel bebas lainnya bernilai tetap, kemudian variabel proses bisnis (X4) mengalami kenaikan 1 satuan maka variabel kepuasan konsumen (Y) mengalami peningkatan sebesar 0,402 atau $40,2 \%$.

\section{d. Uji T}

Tabel 6 Uji T

\begin{tabular}{cccc}
\hline Model & $\mathrm{T}_{\text {tabel }}$ & $\mathrm{T}_{\text {hitung }}$ & Keterangan $\mathrm{T}_{\text {tabel }}<\mathrm{T}_{\text {hitung }}$ \\
\hline $\mathrm{X} 1$ & 1,98 & 0,468 & Tidak Pengaruh Parsial \\
\hline $\mathrm{X} 2$ & 1,98 & 2,921 & Pengaruh Parsial \\
\hline $\mathrm{X} 3$ & 1,98 & 0,527 & Tidak Pengaruh Parsial \\
\hline $\mathrm{X} 4$ & 1,98 & 2,617 & Pengaruh Parsial \\
\hline
\end{tabular}

Pada uji T yaitu uji secara parsial, bahwa variabel harga (X1) tidak berpengaruh secara parsial terhadap variabel kepuasan konsumen (Y). Hal ini disebabkan, harga bakso aci masih belum terjangkau bagi kalangan tertentu, sebab mayoritas konsumenyang digunakan untuk responden sesuai data yang diperoleh dari pemilik usaha bakso aci, berasal dari usia 13 tahun sampai dengan 18 tahun didukung dengan penelitian yang dilakukan oleh (Sari, Anindita, \& Setyowati, 2018), bahwa harga tidak memiliki pengaruh secara signifikan terhadap kepuasan pelanggan pada Coldplay Juice Soji. Mayoritas usia tersebut adalah kalangan pelajar SMP dan SMA. Ditinjau dari variabel inovasi produk (X2), memiliki 
pengaruh terhadap kepuasan konsumen secara parsial, karena inovasi yang diberikan yaitu memiliki jenis isian bermacam - macam, dapat dibawa kemana - mana, dapat bertahan lama jangka tertentu dan praktis dari segi cara memasak, berbeda dengan bakso aci yang berasal dari kota Asalnya yang bertempat di Jawa Barat didukung dengan penelitian yang dilakukan oleh (Daragahi, 2017), bahwa inovasi produk akan memberikan suatu kepuasan bagi konsumen. Sedangkan pada variabel promosi (X3) tidak memiliki pengaruh secara parsial, sebab cara promosi yang dilakukan belum memenuhi sasaran, karena Broadcast melalui WhatsApps belum tentu dibaca oleh penerima pesan tersebut, melakukan penjualan mandiri belum tentu meyakinkan calon pembeli, sebab era saat ini lebih baik menggunakan jasa endorsment. Sedangkan dari tinjauan membuka reseller, belum berjalan efektif sebab reseller yang saat ini menjual bakso aci belum melakukan aktivitas sepenuhnya. Sedangkan pada penyebaran brosur offline, tidak sesuai sasaran karena tampilan brosur belum mampu menarik calon pembeli untuk membeli produk tersebut dan perlu dilakukan penyebaran brosur melalui online. Pada tinjauan aktivitas bisnis, memiliki pengaruh secara parsial sebab packaging dengan plastik tebal lebih diminati pembeli, kemudian cara pendistribusian lewat dropshipper, e-commerce lebih menguntungkan dari pada melalui reseller, sedangkan pembayaran transfer antar bank lebih diminati karena berhubungan dengan pembelian online lebih memudahkan pembeli karena dapat melalui jasa ekspedisi. Oleh karena itu, hipotesis pada $\mathrm{H}_{\mathrm{a}}$ diterima sedangkan $\mathrm{H}_{0}$ ditolak, karena tidak ada hubungan yang berpengaruh secara parsial pada variabel bebas terhadap varaibel terikat. Dari uji secara parsial ini, yang memiliki nilai pengaruh terbesar adalah variabel inovasi produk (X1) karena bakso aci yang dijula berbeda dengan kompetitor didaerah asalnya.

\section{e. Uji F}

Tabel 7 Uji F

\begin{tabular}{ccccc}
\hline Model & $\mathrm{df}$ & $\mathrm{F}_{\text {tabel }}$ & $\mathrm{F}_{\text {hitung }}$ & Keterangan $\mathrm{F}_{\text {tabel }}<\mathrm{F}_{\text {hitung }}$ \\
\hline Regression & 4 & 2,45 & 76,740 & Simultan \\
\hline Residual & 111 & & & \\
\hline Total & 115 & & & \\
\hline
\end{tabular}

Dari uji simultan yang dilakukan variabel bebas yaitu harga, inovasi produk, promosi dan aktivitas bisnis mampu bekerja secara simultan atau bersama - sama terhadap variabel

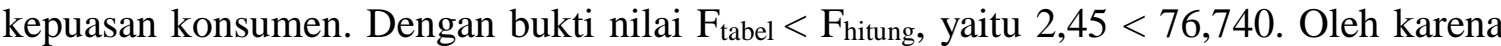
itu, hipotesis yang disimpulkan sesuai dengan $\mathrm{H}_{\mathrm{a}}$ diterima dan $\mathrm{H}_{0}$ ditolak. Hasil penelitian 
didukung oleh (Farida et al., 2016), yaitu pada harga, inovasi produk, promosi, proses bisnis berpengaruh secara simultan.

\section{f. Uji Koefisien Determinasi $\left(\mathbf{R}^{2}\right)$}

Tabel 8 Uji Koefisien Determinasi

\begin{tabular}{cc}
\hline$R$ & $R$ Square \\
\hline 0,857 & 0,734 \\
\hline
\end{tabular}

Pada nilai uji koefisien determinasi yang sudah dihitung, didapatkan bahwa nilai $R$ Square sebesar 0,734 atau 73,4\% yang dijelaskan pada penelitian ini, sedangkan sisanya sebesar 0,266 tidak dijelaskan pada penelitian ini. Dikarenakan penelitian ini, memiliki batasan pada variabel yang digunakan, selain jika ingin mendapatkan nilai $\mathrm{R}$ Square mendekati $100 \%$ diperlukan waktu yang lama.

\section{SIMPULAN \& SARAN}

Berdasarkan penelitian yang sudah dilakukan pengolahan dan pembahasan, dapat disimpulkan bahwa :

1. Variabel harga, inovasi produk, promosi dan proses bisnis tidak berpengaruh terhadap kepuasan konsumen secara parsial.

2. Variabel harga, inovasi produk, promosi dan proses bisnis tidak berpengaruh terhadap kepuasan konsumen secaar simultan.

3. Variabel yang memiliki pengaruh terbesar adalah inovasi produk.

Dari hasil penelitian yang didapatkan, saran - saran yang dapat membangun motivasi agar bisnis bakso aci mengalami peningkatan yaitu melakukan evaluasi terhadap harga produk yang digunakan sebagai nilai tukar didalam pemasaran. Didalam variabel harga perlu dilakukan strategi - strategi agar tetap diminati konsumen. Kemudian dari segi promosi, alangkah lebih baiknya menggunakan jasa endorsement untuk pemasaran produk, kemudian membuka reseller yang memang konsisten dibidang pemasaran bakso aci. Selain itu, bagi peneliti selanjutnya alangkah baiknya dapat melakukan penelitian sebidang dengan penelitian ini, menggunakan lingkup variabel 7P.

\section{DAFTAR PUSTAKA}

Agusta, I. (2014). Teknik Pengumpulan dan Analisis Data Kualitatif. Jurnal Studi Komunikasi Dan Media, 02(1998), 1-11.

Ali Maksum. (2012). Data, Teknik Pengumpulan Data dan Instrumen Penelitian. Jurnal 
Cakrawala Kependidikan, (agustus), 107.

Daragahi, G. (2017). The impact of innovation on customer satisfaction: A study of the cosmetics producer in Tehran. International Review, (1-2), 121-132. https://doi.org/10.5937/intrev1702121d

Dr. Whidmurni, M. P. (2017). Penelitian Kuantitatif. Pemaparan Metodenpenelitian Kuantitatif.

Farida, I., Tarmizi, A., \& November, Y. (2016). Analisis Pengaruh Bauran Pemasaran 7P Terhadap Kepuasan Pelanggan Pengguna Gojek Online. Jurnal Riset Manajemen Dan Bisnis (JRMB) Fakultas Ekonomi UNIAT, 1(1), 31-40. https://doi.org/10.36226/jrmb.v1i1.8

Ghazzan, F. (2012). Pengertian Marketing Mix. Retrieved June 30, 2019, from catatanmarketing.wordpress.com website: https://catatanmarketing.wordpress.com/tag/pengertian-marketing-mix-menurut-kotler/

Hasanah, H. (2017). TEKNIK-TEKNIK OBSERVASI (Sebuah Alternatif Metode Pengumpulan Data Kualitatif Ilmu-ilmu Sosial). At-Taqaddum, 8(1), 21. https://doi.org/10.21580/at.v8i1.1163

I Made Yuliara (Universitas Udayana). (2016). Regresi linier berganda 1. 1-6. Retrieved from http://www.mendeley.com/research/regresi-linier-berganda-1/

Komari, A. (2016). Strategi Pemasaran Produk Indosat M3 di Kota Kediri Berdasarkan Analisis SWOT. 3(2).

Komari, A., Sularso, A., \& Sumiati. (2019). Influence of Marketing Mix against Marketing Performance Through the Orientation of the Batik Small Industry Market In East Java. International Journal of Business and Management Invention, 8(4).

Kotler, P., Kartajaya, H., \& Setiawan, I. (2017). Marketing 4.0 (1st ed.; J. W. \& S. Inc, Hoboken, \& N. Jersey, Eds.). Canada: Inc, John Wiley \& Sons Hoboken Jersey, New.

Kushwaha, G. S., \& Agrawal, S. R. (2015). An Indian customer surrounding 7P[U+05F3]s of service marketing. Journal of Retailing and Consumer Services. https://doi.org/10.1016/j.jretconser.2014.10.006

Rasmansyah. (2017). The effect of service quality and promotion to customer satisfaction and implication of customer loyalty in vehicle financing company in Jakarta Indonesia. International Journal of Advanced Scientific Research, 2(6), 22-30.

Saidani, B., \& R Sudiarditha, I. K. (2019). Marketing Mix-7Ps: The Effect on Customer Satisfaction. Jurnal Pendidikan Ekonomi Dan Bisnis (JPEB), 7(1), 72-86. https://doi.org/10.21009/jpeb.007.1.7

Sari, I., Anindita, R., \& Setyowati, P. (2018). Pengaruh Bauran Pemasaran (Produk, Harga, Tempat dan Promosi) Terhadap Kepuasan Pelanggan Berubah Menjadi Loyalitas Pelanggan Pada Coldplay Juice Soji. Habitat, 29(2), 57-64. https://doi.org/10.21776/ub.habitat.2018.029.2.7

Semiawan, C. R. (2010). Metode Penelitian Kualitatif Jenis, Karakteristik dan Keunggulan (1st ed.). $\quad$ Retrieved from books.google.co.id/books?id=dSpAlXuGUCUC\&printsec=frontcover\#v=onepage \&q\&f $=$ false

Stanton, W. J. (1993). Prinsip Pemasaran (7th ed.). Indonesia: Erlangga.

Subaebasni, S., Risnawaty, H., Arie Wicaksono, A., Albadriyah Widsata, P., Straitliner Express, P., \& APP Jakarta Kemenperin, P. (2019). International Review of Management and Marketing Effect of Brand Image, the Quality and Price on Customer Satisfaction and Implications for Customer Loyalty PT Strait Liner Express in Jakarta. International Review of Management and Marketing, 9(1), 90-97. https://doi.org/10.32479/irmm.7440

Tjiptono, F. (2015). Strategi Pemasaran (Ediri 4). Yogyakarta: ANDI.

Tjiptono, F., \& Chandra, G. (2017). Pemasaran Strategik edisi 3. ANDI.

Widyatama, R. (2016). 7P dalam Bauran Pemasaran. Retrieved September 16, 2019, from Analisis Harga, Inovasi Produk... 
repository.widyatama.ac.id website:

https://repository.widyatama.ac.id/xmlui/bitstream/handle/123456789/2696/Bab 2.pdf? sequence $=7$

Yusup, F. (2018). Uji Validitas dan Reliabilitas Instrumen Penelitian Kuantitatif. Jurnal Tarbiyah: Jurnal Ilmiah Kependidikan. https://doi.org/10.18592/tarbiyah.v7i1.2100 